RESEARCH ARTICLE

\title{
Assessment of Level of Success of Agripreneurs in Tamil Nadu
}

\section{Jayasudha $\mathrm{J}^{1 *}$, Shantha Sheela $\mathbf{M}^{2}$, Venkatesa Palanichamy $\mathbf{N}^{3}$.}

${ }^{1}$ Department of Agricultural Extension and Rural Sociology, Tamil Nadu Agricultural University, Coimbatore - 641003

${ }^{2}$ Directorate of Agri Business Development, Tamil Nadu Agricultural University, Coimbatore - 641003

${ }^{3}$ Department of Agricultural and Rural Management, Tamil Nadu Agricultural University, Coimbatore - 641003

\begin{abstract}
Entrepreneur's success is measured by their ability to succeed as an entrepreneur. Everyone recognizes and categorizes successful entrepreneurs based on their achievements. The present study aimed to assess the level of success of agripreneurs from the agri business incubations of Coimbatore and Madurai. These business incubations were selected purposively because they had been established earlier compared to the other six incubators in Tamil Nadu. The samples were selected by Proportionate random sampling technique. The different dimensions of business success include financial, employment, customer, lifestyle and social responsibility dimension. The study has concluded that the majority ofrespondents had medium level of success in business and also found that financial dimension includes profitability, sales turnover, sales growth, market share, debt level, business growth, return on investment, industrial relations and business image determines the success of the business. The findings of the study suggest that supporting the agripreneurs through financial assistance will lead to the success of agripreneurs.
\end{abstract}

Keywords: Business success; Agripreneurs; Entrepreneurship; Financial dimensions.

\section{INTRODUCTION}

Agripreneurship places a major role in the agricultural industry, which develops entrepreneurs and creates a management workforce (Bairwa et al., 2014). It had major contribution to the economy. Agripreneurs are the persons who take agriculture as business and make profit from it (Nagalakshmi \& Sudhakar, 2013). Entrepreneurial suc cess has been defined in many ways, such as profitability, sustainability, wealth creation (Amit et al., 2000). The success of the enterprise is measured based on organizational performance indicators like sales, profit, company survival, employment growth and return on investment (Chandler \& Hanks, 1998). Both financial and non non-financial characters also determine success. Personal success criteria indicate non-organizational goals such as personal fulfillment, work-related social relationship, self-realization and social recognition. Personal satisfaction is also major one in which entrepreneur should be happy for their enterprise. Strength of financial performance deals with rising equity and debt finance. Profit is mainly decided by the return on investment. Hence, the present study was undertaken to assess the level of success and various dimensions of success of agripreneurs. The dimension of success includes financial, employment, customer, lifestyle and social responsibility dimension.

\section{The objectives of the study were,}

1. To study the different dimensions in the success of agribusiness.

2. To assess the level of success of agripreneurs.

\section{MATERIAL AND METHODS}

The study was conducted among the agripreneurs of Coimbatore and Madurai agri business incubators among the eight incubators in Tamil Nadu. The respondents with minimum of three years of experience was chosen, because the success cannot be assessed in the initial stage of entrepreneurs. The sample size was 104, which was selected by Proportionate random sampling technique from the agri incubators. The variable business success is measured on five-point scale, which consists of statements taken from Irene and in reference with slight modification. The scale consists of categories such as significantly lower, moderately lower, about the same, moderately higher, significantly higher on five-point continuum scale. The data were collected by using pre-tested and well-structured interview schedule. Each agripreneur was personally interviewed to collect the information. The data was 
analyzed using statistical tools such as percentage analysis and mean score method.

\section{RESULTS AND DISCUSSION}

\section{Dimensions of business success}

The business success of agripreneurs was divided into five dimensions, namely financial, employment, customer, lifestyle and social responsibility dimension.

\section{Financial dimension}

The profit mainly determines entrepreneurial success in terms of return on investment of an enterprise. However, the enterprise may be small, medium, or big enterprise, the economic return decides its success. Here, these dimensions include profitability, sales turnover, sales growth, market share, debt level, business growth, return on investment, industrial relations and business image.

Table 1: Ranking of financial dimensions

$(n=104)$

\begin{tabular}{lcc}
\hline Financial dimensions & Mean score & Rank \\
\hline Debt level clearance & 4.59 & $\mathrm{I}$ \\
Profitability & 4.20 & $\mathrm{II}$ \\
Industrial relations & 4.14 & $\mathrm{III}$ \\
Market share & 3.98 & $\mathrm{IV}$ \\
Business growth & 3.84 & $\mathrm{~V}$ \\
Return on investment & 3.81 & $\mathrm{VI}$ \\
Sales turnover & 3.80 & $\mathrm{VII}$ \\
Sales growth & 3.80 & $\mathrm{VII}$ \\
Business image. & 3.76 & $\mathrm{VII}$ \\
\hline
\end{tabular}

Table 1. clearly indicates that debt level clearance is the primary concern of an entrepreneur (4.59). Because decrease in debt level, increases the profit level of the enterprise. It also revealed that profitability (4.20) and industrial relations (4.14) increased the financial assistance of an enterprise. Financial aspects such as market share (3.98); business growth (3.84) and return on investment (3.81) decided the economic success. Sales turnover (3.80), sales growth (3.80) and business image (3.76) were placed at the next, because some of the startups (36.5\%) were below five years of establishment. Hence, it takes time to overcome the break-even point and attaining profit.
Fig.1. Distribution of respondents according to their financial dimension level. $(n=104)$

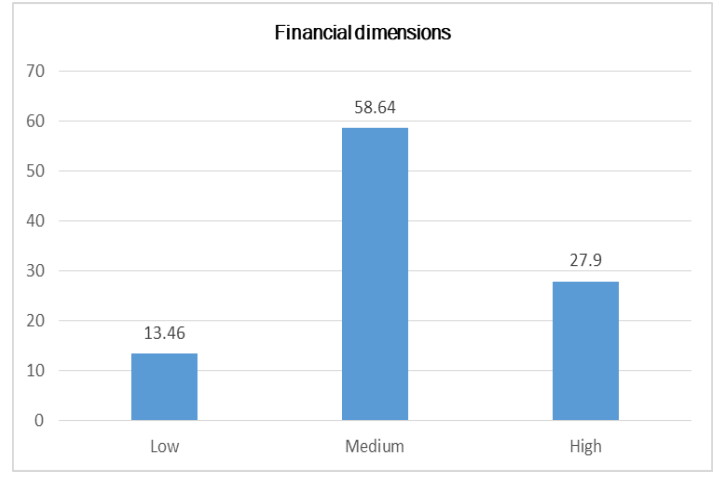

Figure.1. reveals that more than half of the respondents (58.64\%) belonged to medium level, followed by 27.90 per cent of high and 13.46 per cent of low level in financial criteria. Most agripreneurs belonged to the medium category because, more than profit, clearance of debt level was the main concern for them. Without the debt level, running the startups was considered as a success.

\section{Employment dimension}

Creating more employment is one of the criteria for organizational success. The strong organizational setup involvesthe division of work, hence more number of employees can attain theirgoals. This dimension includes number of employees, employee satisfaction, employee absenteeism and employee loyalty.

Table 2: Ranking of employment dimensions

$(n=104)$

\begin{tabular}{lll}
\hline Employment dimensions & Mean score & Rank \\
\hline Employee absentism & 4.66 & I \\
Employee loyalty & 4.30 & II \\
Employee satisfaction & 4.26 & III \\
Number of employees & 3.80 & IV \\
\hline
\end{tabular}

Table 2, reveals that less level of employee absenteeism (4.66)is considered as the success of an enterprise. Employee loyalty (4.30) and employee satisfaction (4.26) revealed that the growth of the enterprise depends on employees. As the enterprise grows, more employees (3.80) could be given job opportunities. Hence, they consider employment as a criterion for the success of business. According to the respondents, rather thanincreasing the number of employees, retaining the existing employee and obtaining their loyalty and satisfaction was considered as successes in their business. 
Fig. 2. Distribution of respondents according to their employment dimension level. $(n=104)$

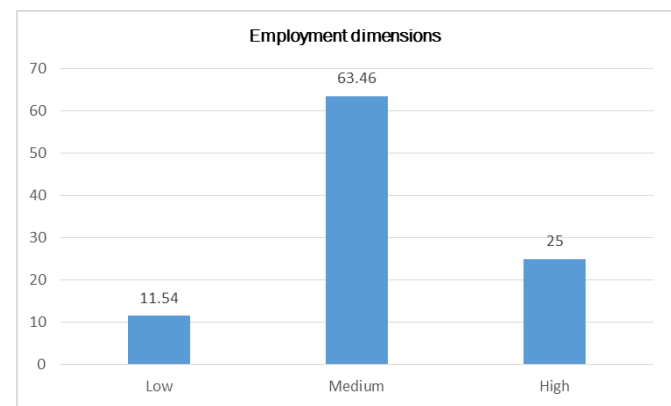

More than half of the respondents $(63.46 \%)$ belonged to the medium level category, followed by 25.00 per cent with high level and 11.54 per cent with low-level category in employment dimension. The reason was that 36.5 per cent of startups had establishment less than five years; hence the employment level was in the medium category (Figure 2).

\section{Customer dimension}

This refers to the degree of customer group stability and the regularity with which the entrepreneur is praised. It encompasses consumer satisfaction, retention, trust, good feedback, and workplace industrial relations.

Table 3: Ranking of customer dimensions $(n=104)$

\begin{tabular}{|lcc|}
\hline \multicolumn{1}{|c}{ Customer dimensions } & Mean score & Rank \\
\hline Customer satisfaction & 4.32 & I \\
Customer retention & 4.30 & II \\
Customer trust & 4.30 & II \\
Good feedback & 4.28 & III \\
Work place industrial relations & 4.26 & IV \\
\hline
\end{tabular}

Table 3, indicates that consumer satisfaction (4.32) is considered as an important factor for business success, followed by customer retention (4.30), customer trust (4.30), good feedback (4.28) and workplace industrial relations (4.26). As we know that satisfied customers were the best source of advertisement, most agripreneur considered customer satisfactionas a major concern in determining success.

Fig.3. Distribution of respondents according to their customer dimension level. $(n=104)$

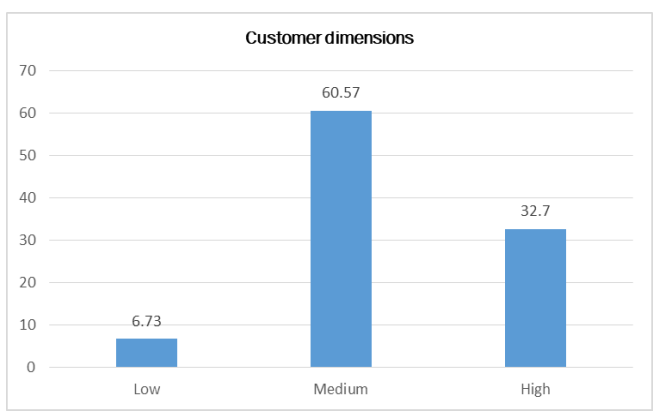

From the Fig.3. majority of the agripreneurs $(60.57 \%)$ had medium level followed by 32.70 per cent of high level and 6.73 per cent of low level in customer dimension level. Because the respondents had considered their customers as the source of business success.

\section{Lifestyle dimension}

Personal satisfaction, career advancement, worklife balance, business survival, and recognition are all factors in lifestyle dimension. The entrepreneur's perception of how the community views them as an individual capability is referred as social recognition.

Table 4: Ranking of life style dimensions ( $n=104)$

\begin{tabular}{lcc}
\hline \multicolumn{1}{c}{ Life style dimensions } & Mean score & Rank \\
\hline Personal satisfaction & 4.32 & I \\
Career progress & 4.26 & II \\
Being recognized by others & 4.26 & III \\
Work and life balance & 4.21 & IV \\
Survival in business & 4.18 & V \\
\hline
\end{tabular}

From the table 4, it is observed that personal satisfaction (4.32) is the lead to the success of the business. Career progress (4.26), being recognized by others (4.26) were essential for an agripreneur to determine their success, followed by work and life balance (4.21) and survival in business (4.18). This indicates that more than earning profit, personal satisfaction was considered as an achievement that an agripreneur can enjoye during their lifetime.

Fig.4. Distribution of respondents according to their life style dimension level.

$(n=104)$

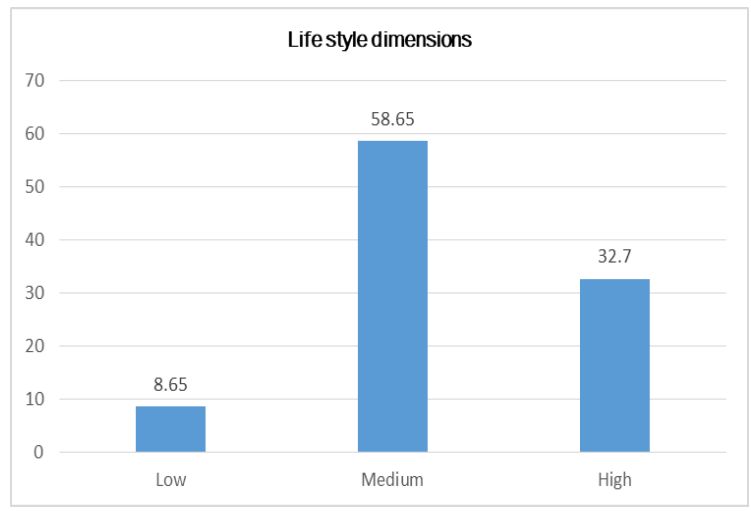

From the Fig.4. it is observed that more than half of the respondents $(58.65 \%)$ are under mediumlevel category followed by high (32.70\%) and low $(8.6 \%)$ level category in life style dimension level. As number of years in business experience increases, the life style also increases.

\section{Social responsibility dimension}

This dimension is measured by factors such as providing a pleasant working environment for employees, creating additional jobs, and 
making products available at a reasonable cost. It demonstrates how the entrepreneur is accountable to his employees and customers.

Table 5: Ranking of social responsibility dimensions

$(n=104)$

\begin{tabular}{lcc} 
Social responsibility dimensions & Mean score & Rank \\
\hline Creating good environment & 4.25 & I \\
Products at affordable price & 4.29 & II \\
Creating more jobs & 4.13 & III \\
\hline
\end{tabular}

Table 5, reveales that creating good environment (4.25) is considered as important social responsibility followed by marketing products at an affordable price (4.29) and creating more jobs (4.13). Every enterprise had some responsibility to contribute to the society; this study showed that creating good environment to both the employee and society were considered as their business success.

Fig.5. Distribution of respondents according to their social responsibility dimension level.

$(n=104)$

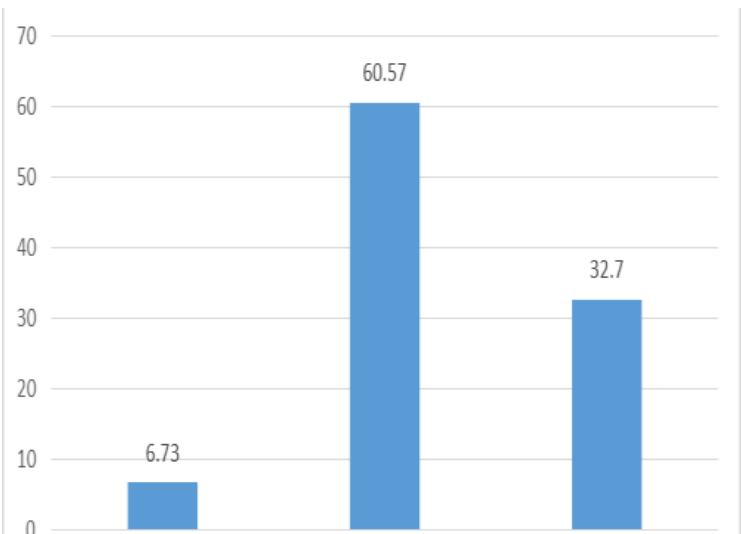

From the Fig.5. majority of the respondents $(60.57 \%)$ belonged to medium level category followed by high (32.70\%) and low (6.73\%) category in social responsibility level.

Table 6. Overall ranking of dimensions in Business success

$(n=104)$

\begin{tabular}{lcc}
\hline \multicolumn{1}{c}{ Dimensions } & Mean score & Rank \\
\hline Financial dimension & 35.92 & I \\
Customer dimension & 21.46 & II \\
Life style dimension & 21.23 & II \\
Employment dimension & 17.02 & III \\
Social responsibility dimension & 12.67 & IV \\
\hline
\end{tabular}

From the table 6 , it is observed that the financial dimension (35.92) is considered as major factor determining the success of agribusiness followed by customer dimension (21.46), life style (21.23), employment (17.02) and social responsibility dimension (12.67).

\section{Level of success of agripreneurs.}

The level of success is measured by the overall value obtained from the different dimensions includes financial, customer, life style, employment and social responsibility dimension.

Fig.6. Distribution of agripreneurs according to the level of success $(n=104)$

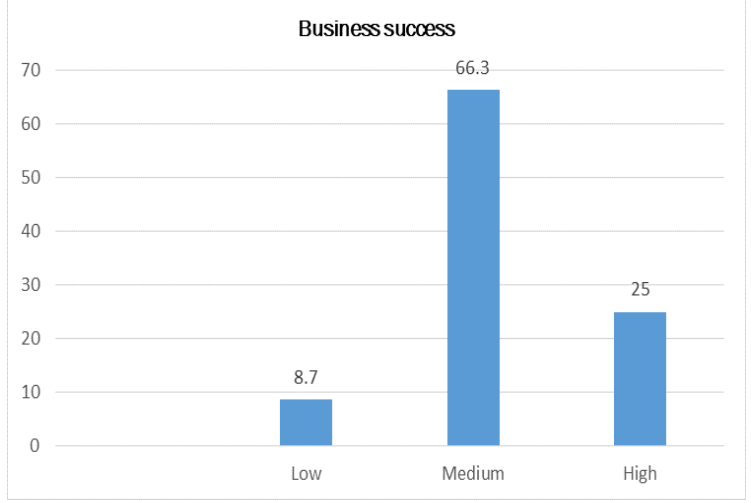

From the Fig.6. it is observed that majority of the respondents (64.00\%) had medium level of success followed by 27.00 per cent and 9.00 per cent of agripreneurs had high and low level of success. The low, medium and high category is classified based on mean and standard deviation obtained from the responses of the agripreneurs.

\section{CONCLUSION}

This study concluded that financial factors were mainly considered as success for agribusiness. Customer satisfaction was also crucial for developing a business. Personal satisfaction will determine the psychological state of an entrepreneur that inturn decide the success of a business. This study also coincides with the findings of Cherukara (2016) which entrepreneurial success is determined by marketing success, followed by organizational, socio psycho satisfaction and meeting obligations. Success is mainly indicated by the net profit and growth in capital. This study suggested that supporting the agripreneurs through financial assistance will lead to the success of agripreneurs.

\section{Declarations \\ Ethics statement}

Specific permits were not required for the above field studies because no human or animal subjects were involved in this research.

\section{Consent for publication}

All the authors agreed to publish the content.

\section{Competing interests}

There was no conflict of interest in the publication of this content. 


\section{Data availability}

All the data of this manuscript are included in the manuscript. No separate external data source is required. If anything is required from the manuscript, certainly, this will be extended by communicating with the corresponding author through corresponding official mail sudhajaganathan98@ gmail.com

\section{REFERENCES}

Amit, R., Mac Crimmon, K., Zietsma, C. and Oesch, J. 2000. Does many matter? Wealth attainment as the motive for initiating growth-oriented technology ventures. J. Bus. Ventur. Insights., 16(2):119 143.

Bairwa, S. L., Kushwaha, S., Meena, L.K., Lakra, K and Kumar, . 2014. Agribusiness potential of North
Eastern states : A SWOT analysis of agribusiness potentials in India: Experience from hill states. EBH publishers, New Delhi. 544 - 556.

Chandler, G. N. and Hanks, S. H. 1993. Measuring the performance of emerging business: A validation study. J. Bus. Ventur. Insights .,8: 391 - 408.

Cherukara, J. M. and Manalel, J. 2016. A definition of entrepreneurial success through empirical study based on MSMEs of Kerala, Int. j. eng. technol. manag. appl. sci., 4 (7).

Nagalakshmi, T and Sudhakar, M. 2013. Agripreneurs: A case study of Dharmapuri farmers. Int. J. Sci. Res., 12 (8): 208 - 214. 197

Irene, Bridget. 2016. Gender and entrepreneurial success: A cross cultural study of competencies of female SMEs operators in South Africa. Cardiff Metropolitan University. 